\title{
Transvalencin A, a Thiazolidine Zinc Complex Antibiotic Produced by a Clinical Isolate of Nocardia transvalensis
}

\section{Taxonomy, Fermentation, Isolation and Biological Activities}

\author{
YASUTAKa HOSHINO ${ }^{\mathrm{a}, \mathrm{b}}$, AKIRA MUKaI $^{\mathrm{a}}$, KATSUKIYO YAZAWA ${ }^{\mathrm{a}}$, JUN UNO ${ }^{\mathrm{a}}$, JUn ISHIKAWA ${ }^{\mathrm{b}}$, \\ AKIKAZU ANDO ${ }^{c}$, TOSHIO FUKal ${ }^{\text {d }}$ and YUZURU MiKami*a \\ a Research Center for Pathogenic Fungi and Microbial Toxicoses, Chiba University, \\ 1-8-1, Inohana, Chuo-ku, Chiba, Chiba 260-8673, Japan \\ ${ }^{b}$ Department of Bioactive Molecules, National Institute of Infectious Diseases, \\ 1-23-1, Toyama, Shinjuku, Tokyo 162-8640, Japan \\ ${ }^{\mathrm{c}}$ Department of Biotechnology, Graduate School of Science and Technology, Chiba University, \\ 1-33 Yayoi-cho, Inage-ku, Chiba, Chiba 263-8522, Japan \\ ${ }^{d}$ School of Pharmaceutical Sciences, Toho University, \\ 2-2-1, Miyama, Funabashi, Chiba 274-8510, Japan
}

(Received for publication August 31, 2004)

A new thiazolidine-type antibiotic with zinc in its structure, designated transvalencin A, was isolated from Nocardia sp. IFM 10065, a clinical isolate from a patient with actinomycotic mycetoma. The strain was identified as Nocardia transvalensis based on its morphological, phenotypic and phylogenetic characteristics. Transvalencin A showed antimicrobial activity against fungi such as Trichophyton mentagrophytes and Cryptococcus neoformans. The antibiotic is also active against Gram-positive bacteria such as Micrococcus luteus. We observed higher activity for fungi in an acidic medium than in a neutral medium.

Human nocardioses are caused by members of the Nocardia asteroides complex (N. asteroides sensu stricto, $N$. farcinica, and $N$. nova), $N$. brasiliensis, $N$. otitidiscaviarum, and $N$. transvalensis. ${ }^{1,2)}$ We have isolated several new bioactive compounds from clinical isolates of Nocardia strains. $^{3 \sim 5)}$ Most bioactive compounds were produced by strains of $N$. brasiliensis. ${ }^{4 \sim 9)}$ However, we recently isolated new bioactive compounds from non- $N$. brasiliensis species such as $N$. pseudobrasiliensis and $N$. asteroides. ${ }^{10 \sim 12)}$ During our continuing studies of biologically active compounds from non- $N$. brasiliensis clinical isolates, we isolated a new antifungal compound, designated as transvalencin A (Fig. 1), from the mycelial cake of a clinical isolate of Nocardia sp. strain IFM 10065 obtained from a patient with actinomycotic mycetoma. This paper describes the taxonomy of the producing organism, fermentation, isolation, physicochemical properties, and biological activities of the antibiotic. Structural elucidation of the compound is reported in a subsequent paper.

Fig. 1. Structure of transvalencin A.

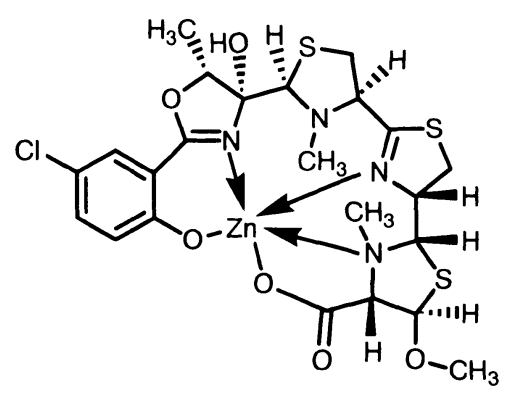

\footnotetext{
* Corresponding author: mikami@faculty.chiba-u.jp
} 


\section{Material and Methods}

Taxonomic Studies

Nocardia sp. strain IFM 10065 was isolated in 2001 from a 65-year-old Japanese male patient with actinomycotic mycetoma. The strain IFM 10065 was cultured on a Mueller Hinton II agar slant (MHII; Difco Laboratories, USA) with $1 \%$ glucose and $1 \%$ glycerol for 1 week at $27^{\circ} \mathrm{C}$. For extraction of DNA and its sequencing, the bacterial strain was cultured on brain heart infusion (BHI; Difco Laboratories, USA) broth for 4 days at $32^{\circ} \mathrm{C}$.

Physiological and biochemical characterization of the strain was done by method described previously. Decomposition of various compounds such as adenine and casein were undertaken using methods of GORDON et al. ${ }^{13)}$ Acid production tests using various carbohydrates, utilization of organic acids, and growth temperature were determined by the modified method of PoONWAN et al. ${ }^{14)}$ Whole cell hydrolysates were analyzed for diaminopimelic acid (DAP) isomers and for cell wall sugars using thin layer chromatography (TLC). ${ }^{15.16)}$ Menaquinones were extracted from freeze-dried biomass $(500 \mathrm{mg})$ and analyzed as described by Chun \& Goodfellow. ${ }^{17)}$ Mycolic acids were analyzed using the procedure of MINNIKIN et al. ${ }^{18)}$ Genomic DNA samples were prepared using the guanidine thiocyanate method. ${ }^{19.20)} 16 \mathrm{~S}$ rDNA was amplified by PCR and sequenced using prokaryotic $16 \mathrm{~S}$ rDNA universal primers. ${ }^{17)}$ DNA sequences were determined using an automated sequence analyzer (ABI PRISM ${ }^{\mathrm{TM}}$ 3100; PE Applied Biosystems, USA). BLAST analysis was used to screen databases for strains related to the isolate. ${ }^{21}$ The $16 \mathrm{~S}$ rDNA sequence of the isolate was determined. These data were used for phylogenetic analysis. A phylogenetic tree was produced using the neighbor-joining method. ${ }^{21,22)}$

\section{Fermentation and Isolation}

A slant culture of Nocardia sp. strain IFM 10065 grown on MHII medium supplemented with $0.2 \%$ glucose was used throughout this work. The seed broth was prepared by inoculating a slant culture of the producing strain IFM 10065 into a 100-ml Erlenmeyer shake flask containing $50 \mathrm{ml}$ of BHI broth supplemented with $1 \%$ glucose and $1 \%$ glycerol. This broth was cultured at $32{ }^{\circ} \mathrm{C}$ for 4 days on a rotary shaker at $300 \mathrm{rpm}$. We transferred $10 \%$ inoculum into a $500-\mathrm{ml}$ Erlenmeyer flask containing $150 \mathrm{ml}$ of the production medium comprising meat extract $0.5 \%$, peptone $0.5 \%$, glycerol $2.0 \%$, and antifoam $0.05 \%$. The culture was incubated on a rotary shaker at $(250 \mathrm{rpm})$ at $32^{\circ} \mathrm{C}$ for 6 days. $^{10)}$
Antimicrobial Activity

Antimicrobial activities were determined using the micro-broth dilution method. The test used BHI broth media adjusted to $\mathrm{pH} 6.0$ or 7.0 with the following microorganisms: Micrococcus luteus IFM 2066, Escherichia coli NIH JC-2, Candida albicans ATCC 90028, Cryptococcus neoformans ATCC 90112, Aspergillus niger IFM 5368, Paecilomyces variotii IFM 40913 and Trichophyton mentagrophytes IFM 10489. After inoculation, test bacteria and fungi were incubated at $37^{\circ} \mathrm{C}$ for 24 and 48 hours, respectively; thereafter, the MIC values were determined.

\section{Results and Discussion}

\section{Taxonomy of Producing Strain IFM 10065}

The strain IFM 10065 is an aerobic Gram-positive, acid fast, non-motile microorganism. It forms a grayish-orange to a faint-orange-colored substrate mycelium that fragments into irregular rod-shaped elements, which is characteristic of Nocardia (Fig. 2).

Chemotaxonomic characteristics of the strain IFM 10065 were consistent with its assignment to the genus Nocardia. ${ }^{23,24)}$ The strain contained galactose and arabinose as characteristic whole-cell wall sugars in addition to mesodiaminopimelic acid as the diagnostic cell-wall diamino acid. The strain IFM 10065 also contained mycolic acid, which co-migrates with that extracted from Nocardia type strains. The major menaquinone was $\mathrm{MK}-8\left(\mathrm{H}_{4(1)-c y c)}\right)$; it was

Fig. 2. Scanning electron micrograph of Nocardia transvalensis IFM 10065 grown on $\mathrm{MH}$ II agar medium supplemented with $0.2 \%$ glucose at $30^{\circ} \mathrm{C}$ for 7 days.

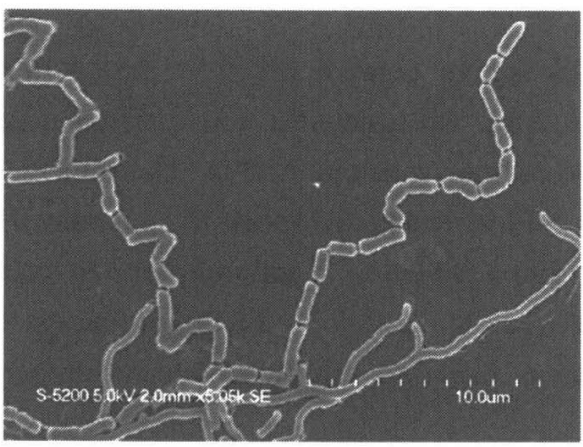


Fig. 3. The phylogenetic tree shows the position of Nocardia sp. IFM 10065 within the genus Nocardia species based on the 16S RNA gene sequences.

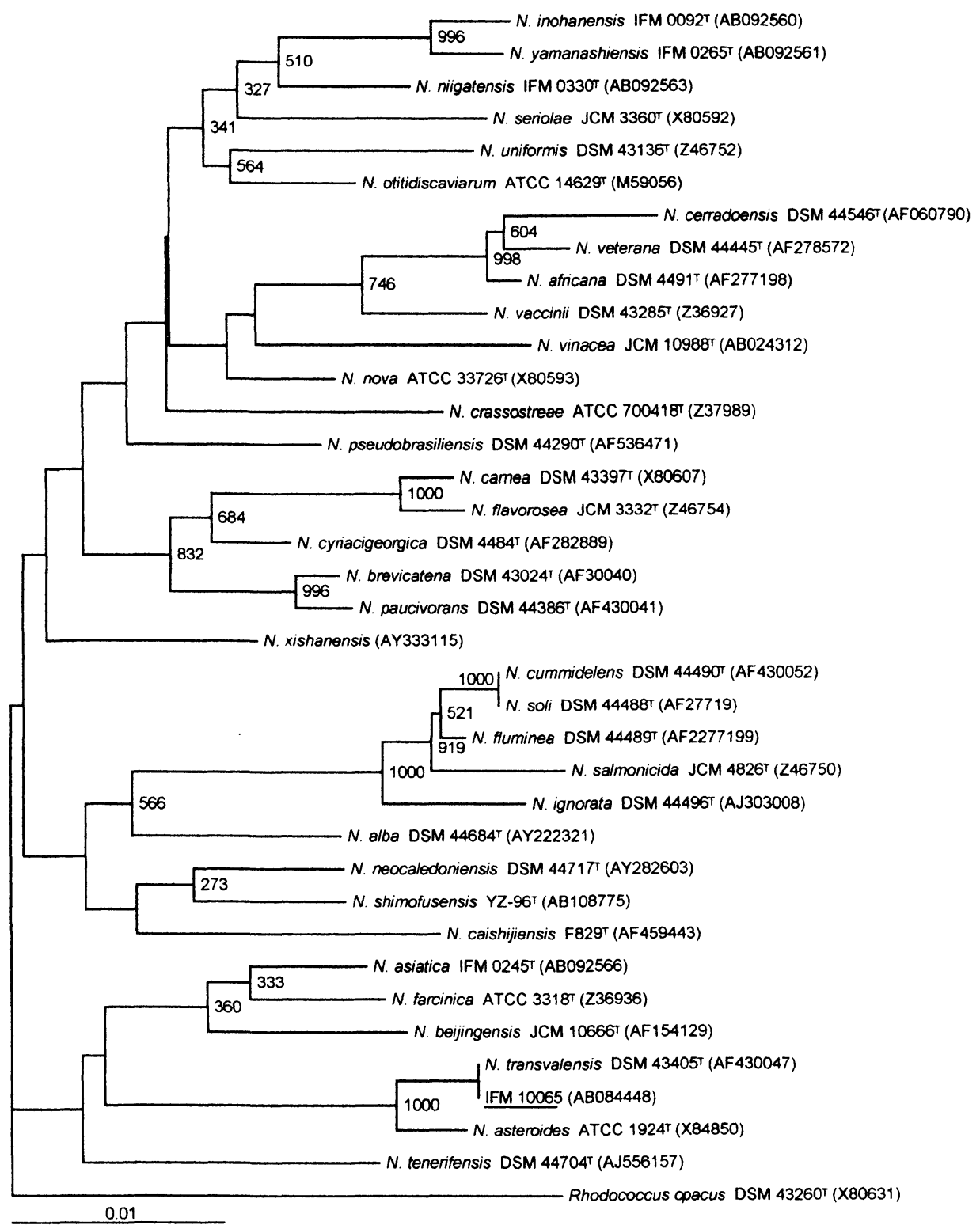

identical to that of a typical Nocardia strain. On the basis of typical nocardioform morphology with cell wall type IV, coupled with the chemotypes of mycolic acid and menaquinone, strain IFM 10065 was inferred to be a member of the genus Nocardia.

We determined the $16 \mathrm{~S}$ rDNA sequence of the strain IFM 10065. A database search revealed that the strain belonged to the genus Nocardia, the suborder Corynebacterineae of the family Nocardiaceae. ${ }^{25)}$ The phylogenetic tree (Fig. 3) showed that the strain is highly associated with $N$. transvalensis.

A comparison of physiological characteristics of IFM 10065 with the type strain of $N$. transvalensis IFM 0333 indicated that it was a strain of $N$. transvalensis (Table 1). Thus IFM 10065 was identified as $N$. transvalensis based on these phylogenetic, physiological, and biochemical characteristics. 
Table 1. Physiological characteristics of Nocardia sp. strain IFM 10065.

\begin{tabular}{|c|c|c|c|c|c|}
\hline Characteristics & IFM 10065 & 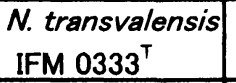 & Characteristics & IFM 10065 & 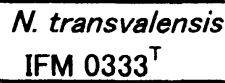 \\
\hline & & & maltose & - & - \\
\hline Decomposition of & & & mannose & - & - \\
\hline adenine & $-{ }^{a}$ & - & mamnose & - & - \\
\hline casein & - & - & sorbitol & - & + \\
\hline hypoxanthine & $+t^{b}$ & & Utilization of & & \\
\hline tyrosine & - & - & citrate & + & + \\
\hline urea & + & + & Growth at & & \\
\hline xanthine & - & - & $45^{\circ} \mathrm{C}$ & - & - \\
\hline Acid from & & & Production of & & \\
\hline adonitol & + & + & $\beta$-lactamase & + & + \\
\hline arabinose & - & - & Susceptibility to & & \\
\hline enythritol & + & + & imipenem & $++t^{c}$ & +++ \\
\hline galactose & + & + & tobramycin & - & - \\
\hline glucose & + & + & 5-fluorouracil & $\pm^{d}$ & \pm \\
\hline inositol & - & + & kanamycin & - & - \\
\hline
\end{tabular}

a: negative reaction, b: positive reaction, c: highly susceptible, $d$ : marginal growth inhibition around $30 \mu \mathrm{g}$ of 5 -fluorouracil containing paper-disc can be observed

Fermentation, Isolation and Physico-chemical Properties

After 7 days' incubation, one half volume of methanol was added to the mycelial cake; it was incubated for another 3 hours to kill the Nocardia and extract the active compound. The extract was filtered and concentrated in vacuo. After addition of $100-\mathrm{ml}$ water to the concentrated fraction, it was extracted with the same volume of ethyl acetate. The extract was concentrated in vacuo: a crude residue was subjected to silica gel column chromatography using $\mathrm{CHCl}_{3}$. The combined active fractions were purified further using silica gel column chromatography with a mixture of toluene and ethyl acetate $(3: 1)$. The active fractions were further purified by preparative thin layer chromatography (TLC) using the mixture of toluene : ethyl acetate $(3: 1)$ as eluent. The active compound was applied to Sephadex LH-20 column chromatography $\left(\mathrm{CHCl}_{3}\right.$ :methanol=1:1). The purified compound was obtained by preparative reverse phase HPLC (ODS $-10 \times 250 \mathrm{~mm}, 35 \sim 65 \% \quad \mathrm{CH}_{3} \mathrm{CN}$ linear gradient, $5 \mathrm{ml} /$ minute, $250 \mathrm{~nm}$; Jasco Inc.). Final purification was carried out by HPLC (ODS $-10 \times 250 \mathrm{~mm}$; methanol, $5 \mathrm{ml} /$ minute, $250 \mathrm{~nm}$; Jasco Inc.) to obtain $7.2 \mathrm{mg}$ of transvalencin $\mathrm{A}$.
Table 2. Antimicrobial activity of transvalencin A against bacteria and fungi.

\begin{tabular}{lcc}
\hline test organism & \multicolumn{3}{c}{ MIC values $(\mu \mathrm{g} / \mathrm{ml})$} \\
& $\mathrm{pH} 7.3$ & $\mathrm{pH} 6.0$ \\
\hline Micrococcus luteus IFM 2066 & 16 & 0.5 \\
Escherichia coli NIH JC-2 & $>32$ & $>32$ \\
Candida albicans ATCC 90028 & $>32$ & $>32$ \\
Cryptococcus neoformans ATCC 90112 & 4 & $>32$ \\
Aspergillus niger IFM 5368 & $>32$ & $>32$ \\
Paecilomyces variotii IFM 40913 & 16 & $>32$ \\
Trichophyton mentagrophytes IFM 10489 & 2 & 8
\end{tabular}

MIC was determined by microplate dilution method using BHI medium.

\section{Biological Properties}

Table 2 shows in vitro antibacterial activities of transvalencin $\mathrm{A}$. The antibiotic was active against fungi and Gram-positive bacteria, but was not active against the Gram-negative bacteria tested. MIC values against $C$. neoformans ATCC 92112, T. mentagrophytes IFM 10489, and $P$. variotii IFM 40913 were $4.0,16.0$, and $2.0 \mu \mathrm{g} / \mathrm{ml}$ on BHI medium ( $\mathrm{pH}$ 7.3), respectively. However, lower activities against fungi such as T. mentagrophytes IFM 
10489, C. neoformans ATCC 90112, and P. variotti IFM 40913 were observed in the acid medium with a $\mathrm{pH}$ of 6.0 . The MIC value against $M$. luteus IFM 2066 is $16.0 \mu \mathrm{g} / \mathrm{ml}$ on BHI medium with a $\mathrm{pH} 7.3$, but higher activity was observed in acidic BHI medium, such as $\mathrm{pH}$ 6.0.

\section{Acknowledgements}

We thank Drs. T. TAmura and K. SuzuKı (National Institute of Technology and Evaluation) for advice regarding scanning electron microscopic observation. This work received partial support (to Y. M.) from the "Frontier Studies and International Networking of Genetic Resources in Pathogenic Fungi and Actinomycetes (FN-GRPF)" program through Special Cooperation Funds for Promoting Science and Technology from the Ministry of Education, Culture, Sports, Science and Technology, Japan (2001 2003).

\section{References}

1) Beaman, B. L. \& L. Beaman: Nocardia species: Hostparasite relationship. Clin. Microbiol. Rev. 7: 213 264, 1994

2) Kageyama, A.; K. Yazawa, J. Ishizawa, K. Hotta, K. NishimURA \& Y. MIKAMI: Nocardial infections in Japan from 1992 to 2001, including the first report of infection by Nocardia transvalensis. Eur. J. Epidemiol. 19: 383 389, 2004

3) Mikami, Y.; K. Yazawa, S. Ohashi, A. Maeda, M. AKAO, M. ISHIBASHI, J. KOBAYASHI \& C. YAMAZAKI: SO75R1, a new mutactimycin derivative produced by Nocardia brasiliensis. J. Antibiotics 45: 995 997, 1992

4) Tsuda, M.; H. Sato, Y. Tanaka, K. Yazawa, Y. Mikami, T. SaSAKI \& J. Kobayashi: Brasiliquinones $A \sim C$, new cytotoxic benz $[a]$ anthraquinones with an ethyl group at C-3 from actinomycete Nocardia brasiliensis. J. Chem. Soc. Perkins Trans. 1: 1773 1775, 1996

5) Shigemori, H.; H. Komaki, K. Yazawa, Y. Mikami, A. Nemoto, Y. TANaka, T. SASAKI, Y. In, T. Ishida \& J. KOBAYASHI: Brasilicardin A. A novel tricyclic metabolite with potent immunosuppressive activity from actinomycete Nocardia brasiliensis. J. Org. Chem. 63: 6900 6904, 1998

6) Shigemori, H.; Y. Tanaka, K. Yazawa, Y. Mikami \& J. KoBayashi: Brasilinolide A. A new immunosuppressive macrolide from actinomycete Nocardia brasiliensis. Tetrahedron 52: 9031 9034, 1996

7) Mikami, Y.; H. Komaki, T. Imai, K. Yazawa, A. Nemoto, Y. Tanaka \& U. Graefe: A new antifungal macrolide component, brasilicardin $\mathrm{B}$ produced by Nocardia brasiliensis. J. Antibiotics 53: 70 74, 2000

8) Kobayashi, J.; M. Tsuda, A. Nemoto, Y. Tanaka, K. YAZAWA \& Y. Mikami: Brasilidine A, a new cytotoxic isonitrile-containing indole alkaloid from the actinomycete Nocardia brasiliensis. J. Nat. Prod. 60: 719 720, 1997

9) Nemoto, A.; Y. Tanaka, Y. Karasaki, H. Komaki, K. Yazawa, Y. Mikami, T. Tojo, K. Kadowaki, M. Tsuda \& J. KoBAYASHI: Brasiliquinones $\mathrm{A}, \mathrm{B}$ and $\mathrm{C}$, new benz $[a]$ anthraquinone antibiotics from Nocardia brasiliensis. I. Producing strain, isolation and biological activities of the antibiotics. J. Antibiotics 50: 18 21, 1997

10) Speitling, M.; P. Nattewan, K. Yazawa, Y. Mikami, I. Grun-Wollny, M. Ritzau, H. Laatsch \& U. Grafe: Demethyl mutactimycins, new anthracycline antibiotics from Nocardia and Streptomyces strains. J. Antibiotics 51: 693 698, 1998

11) Tanaka, Y.; U. Graefe, K. Yazawa, Y. Mikami \& M. RitzaU: Nocardicyclins A and B: new anthracycline antibiotics produced by Nocardia pseudobrasiliensis. J. Antibiotics 50: 822 827, 1997

12) Nemoto, A.; Y. Hoshino, K. Yazawa, A. Ando, Y. Mikami, H. Komaki, Y. TanaKa \& U. Grafe: Asterobactin, a new siderophore group antibiotic from Nocardia asteroides. J. Antibiotics 55: 593 597, 2002

13) Gordon, R. E. D.; A. Barnett, J. E. Handerhan \& C. N. N. PANG: Nocardia coeliaca, Nocardia autotrophica, and the nocardin strain. Int. J. Syst. Bacteriol. 24: $54 \sim 63,1974$

14) Poonwan, N.; M. Kusum, Y. Mikami, K. Yazawa, Y. Tanaka, T. Gonol, S. Hasegawa \& K. Konyama: Pathogenic Nocardia isolated from clinical specimens including those of AIDS patients in Thailand. Eur. J. Epidemiol. 11: 507 512, 1995

15) Lechevalier, M. P. \& H. A. Lechevalier: The chemotaxonomy of actinomycetes. In Actinomycete Taxonomy. pp. 227 291. Edited by A. Dietz \& D. W. ThAYER. Society for Industrial Microbiology: Virginia, 1980

16) MiyadoH, M.: Identification procedure at the genus level. In Identification Manual of Actinomycetes. pp. 9 19. Edited by S. Miyadoh, M. Hamada, K. Hotta, T. Kudo, A. Seino, K. SuzuKi \& A. Yokota. Business Center For Academic Societies Japan: Tokyo, 2001

17) Chun, J. \& M. Goodfellow: A phylogenetic analysis of genus Nocardia with 16S rRNA gene sequences. Int. J. Syst. Bacteriol. 45: 240 245, 1995

18) Minnikin, D. E.; I. J. Hutchinson, A. B. Caldicott \& M. GoOdFEllow: Thin-layer chromatography of methanolysates of mycolic acid containing bacteria. J. Chromatogr. 188: 221 233, 1980

19) Kageyama, A.; N. Poonwan, K. Yazawa, Y. Mikami \& K. Nishimura: Nocardia asiatica sp. nov., isolated from patients with nocardiosis in Japan and clinical specimens from Thailand. Int. J. Syst. Evol. Microbiol. 54: 125 130, 2004

20) Kageyama, A.; K. Yazawa, N. Nishimura \& Y. Mikami: Nocardia inohanensis sp. nov. Nocardia yamanashiensis sp. nov., and Nocardia niigatensis sp. nov. isolated from clinical specimens. Int. J. Syst. Evol. Microbiol. 54: $563 \sim 569,2004$

21) Saitou, N. \& M. NeI: The neighbor-joining method: a new method for reconstructing phylogenetic trees. Mol. Biol. Evol. 4: 406 425, 1987

22) Thompson, J. D.; D. G. Higgins \& T. J. Gibson: CLUSTAL W: Improving the sensitivity of progressive multiple sequence alignment through sequence weighting, position specific gap penalties and weightmatrix choice. Nucleic Acid Res. 22: 4673 4680, 1994

23) Kageyama, A.; K. Torikoe, M. Inamoto, J. Masuyama, Y. Shibuya, H. Okazaki, K. Yazawa, S. Minota, R. M. 
Kroppenstedt \& Y. Mikami: Nocardia arthritidis sp. nov., a new pathogen isolated from a patient with rheumatoid arthritis in Japan. J. Clin. Microbiol. 42: 2366 2371, 2004.

24) Goodfellow, M.: Nocardia and related genera. In Topley and Wilson's Microbiology and Microbial Infections, 9th edn., Vol. 2, Systematic Bacteriology, pp.
463 489. Edited by A. Balows \& B. I. Duerden. London, Arnold, 1998

25) Stackebrandt, E.; F. A. Rainey \& N. L. Ward-Rainey: Proposal for a new hierarchic classification system, Actinobacteria class nov. Int. J. Syst. Bacteriol. 47: 479 491, 1997 